\title{
Avaliação do nível de conhecimento dos acadêmicos do primeiro ano do curso de Odontologia da UEM sobre avulsão dentária
}

Evaluation of the level of knowledge of the students of the first year of the dental course of UEM about dental avulsion

Evaluación del nivel de conocimiento de los alumnos del primer año del curso de Odontología de la UEM sobre avulsión dental

Maria Luisa Gomes FERREIRA ${ }^{1}$

Isabela WEBER $\mathbf{W}^{\mathbf{1}}$

Nair Narumi Orita PAVAN ${ }^{2}$

Najara Barbosa da ROCHA ${ }^{2}$

Marcos Sérgio ENDO ${ }^{2}$

${ }^{1}$ Graduanda em Odontologia, Universidade Estadual de Maringá, UEM, Departamento de Odontologia, 87083-170 Maringá - PR, Brasil

${ }^{2}$ Docente do curso de Odontologia da Universidade Estadual de Maringá, UEM, Departamento de Odontologia, 87083-170 Maringá - PR, Brasil

\section{Resumo}

Introdução: A avulsão dentária caracteriza-se pelo total deslocamento do dente para fora do seu alvéolo representando uma lesão complexa e dramática que pode afetar múltiplos tecidos. Representa uma situação de urgência, e o prognóstico depende de um tratamento rápido e apropriado. Objetivo: Este estudo tem como objetivo avaliar o nível de conhecimento dos alunos do curso de Odontologia do primeiro ano da Universidade Estadual de Maringá (UEM) sobre a avulsão dentária, abordando a forma de atuação clínica e conduta que deve ser adotada frente a esse tipo de traumatismo dentário. Material e método: Elaborou-se um questionário, contendo dados gerais e informações relacionadas a avulsão dentária. O questionário foi aplicado na aula de introdução à Endodontia aos acadêmicos do primeiro ano. As informações obtidas foram tabuladas e analisadas por meio de uma estatística descritiva. Resultados: Os resultados sugerem que o conhecimento sobre o manejo de dentes avulsionados é insuficiente entre os estudantes do primeiro ano de Odontologia. Conclusão: Dessa forma, a educação odontológica deve focar nas orientações sobre primeiros socorros em lesões odontológicas e enfatizar a necessidade de disseminar programas de treinamento e educação para os estudantes de Odontologia.

Descritores: Traumatismos Dentários; Avulsão Dentária; Odontologia.

\section{Abstract}

Introduction: Tooth avulsion is characterized by the complete displacement of the tooth out of your alveolus, representing a complex and dramatic lesion that can affect multiple tissues. It represents an emergency situation, and the prognosis depends on fast and appropriate treatment. Objective: This study aims to evaluate the level of knowledge of dentistry students from the first year of the State University of Maringá (UEM) about dental avulsion, addressing the form of clinical practice and conduct that should be adopted in the face of this type of dental trauma. Material and method: A questionnaire was elaborated, containing data and information related to tooth avulsion. The questionnaire was applied in the endodontics introduction class to first year students. The information obtained was tabulated and analyzed using descriptive statistics. Results: The results suggest that the knowledge about the management of avulsed teeth is insufficient among the first year students of dentistry. Conclusion: Thus, dental education should focus on first aid guidance on dental injuries and emphasize the need to disseminate training and education programs for dental students.

Descriptors: Tooth Injuries; Tooth Avulsion; Dentistry.

\section{Resumen}

Introducción: La avulsión dental se caracteriza por el desplazamiento completo del diente fuera de su cavidad, lo que representa una lesión compleja y dramática que puede afectar a múltiples tejidos. Representa una situación de emergencia, y el pronóstico depende de un tratamiento rápido y apropiado. Objetivo: Este estudio tiene como objetivo evaluar el nivel de conocimiento de los estudiantes de odontología del primer año de la Universidad Estatal de Maringá (UEM) sobre avulsión dental, abordando la forma de práctica clínica y conducta que debe adoptarse contra este tipo de trauma dental. Material y método: se elaboró un cuestionario que contenía datos generales e información relacionada con la avulsión dental. El cuestionario se aplicó en la clase de introducción de endodoncia a estudiantes de primer año. La información obtenida se tabuló y analizó mediante estadística descriptiva. Resultados: Los resultados sugieren que el conocimiento sobre el manejo de los dientes con avulsión es insuficiente entre los estudiantes de primer año de odontología. Conclusión: Por lo tanto, la educación dental debe centrarse en la orientación de primeros auxilios sobre lesiones dentales y enfatizar la necesidad de difundir programas de capacitación y educación para estudiantes de odontología.

Descriptores: Traumatismos de los Dientes; Avulsión de Diente; Odontología.

\section{INTRODUÇÃO}

O traumatismo dentário corresponde a um conjunto de impactos que afeta os dentes e suas estruturas de suporte; por sua vez, a avulsão dentária caracteriza-se pelo total deslocamento do dente para fora do seu alvéolo representando uma lesão complexa e dramática que pode afetar múltiplos tecidos e, diante de tal situação, recomenda-se o imediato reimplante dentário ${ }^{1}$.

As causas da avulsão dentária estão relacionadas com a ocorrência de um trauma, que pode ser causado por quedas, colisões contra objetos, superfícies ou pessoas, acidentes automobilísticos, práticas esportivas, violência, brincadeiras agressivas ou ocupacional ${ }^{2,3}$.

O traumatismo dentário e em particular a avulsão dentária é uma situação de urgência, e o prognóstico depende de um tratamento rápido e apropriado, que muitas vezes se baseia no conhecimento de pais e responsáveis, que estão presentes no local do acidente ${ }^{1,4}$.

Quando um dente avulsionado é recuperado, existem duas situações que podem ocorrer, sendo o ideal o reimplante imediato no alvéolo restaurando assim a estética e função do paciente. $\mathrm{O}$ outro cenário, muito mais frequentemente encontrado, é o dente não ser imediatamente reimplantado, mas trazido ao dentista para o reimplante. Dessa forma, para um bom prognóstico fatores como armazenamento, transporte e tempo decorrido desde o trauma estão diretamente relacionados à manutenção da vitalidade das células da polpa e do ligamento periodontal ${ }^{3,5}$. 
O tratamento para os casos de avulsão é, de certa maneira, complexo, pois além de ser demorado e relativamente caro, necessita de cuidados multidisciplinares como Endodontia, Periodontia, Cirurgia, Ortodontia, Radiologia, Odontopediatria e Restaurações estéticas ${ }^{6,7}$. Dessa forma, é de fundamental importância que o cirurgião-dentista se mantenha permanentemente atualizado quanto a esse tipo de lesão levando assim a condutas terapêuticas adequadas melhorando o seu prognóstico.

Este estudo tem como objetivo avaliar o nível de conhecimento dos alunos do curso de Odontologia do primeiro ano da Universidade Estadual de Maringá (UEM) sobre a avulsão dentária, abordando a forma de atuação clínica e conduta que deve ser adotada frente a esse tipo de traumatismo dentário.

\section{MATERIAL E MÉTODO}

Este estudo utilizou um questionário (Figura 1) composto por 14 questões, formuladas pelos autores, com base em trabalhos publicados anteriormente. Os dados foram tabulados em 2019 referentes a duas turmas que passaram pelo primeiro ano do curso de Odontologia da UEM, nas aulas de Endodontia. O projeto foi eticamente aprovado pela Universidade Estadual de Maringá.

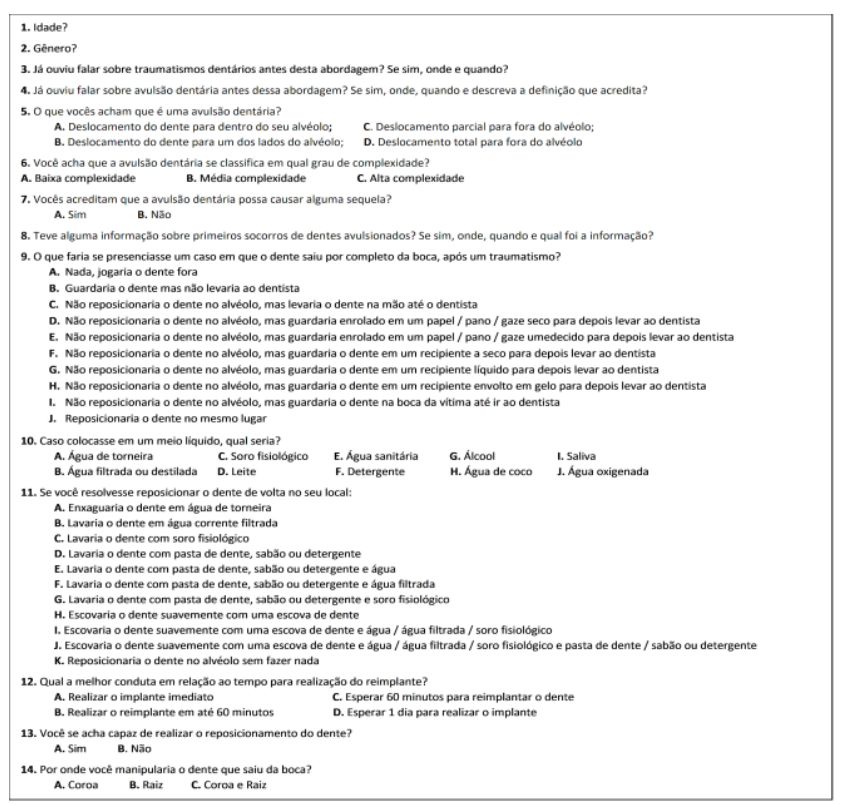

Figura 1: Questionário aplicado aos estudantes de Odontologia.

As questões abordaram informações pessoais como idade e sexo, seguidas da busca de dados relacionados ao conhecimento dos alunos sobre avulsão dentária, como: influência do período extra alveolar, meio de armazenamento do dente avulsionado e a conduta do cirurgião-dentista relacionada a este tipo de trauma.

Todos os participantes deram seu consentimento antes da participação no estudo. Para garantir o anonimato, nenhum nome ou outra informação pessoal foi registrada. Os dados dos alunos do primeiro ano foram analisados por estatística descritiva.

\section{RESULTADOS}

O questionário foi preenchido por 76 estudantes de Odontologia da UEM. A idade dos estudantes do primeiro ano variou de 17 a 24 anos, com média de idade de 18,5 anos (dp $\pm 1,74$ ). Entre os que responderam, 60 estudantes eram do sexo feminino (79\%) e 16 (21\%) eram do sexo masculino (Tabela 1).

Tabela 1 - Distribuição de gênero e idade entre acadêmicos entrevistados.

\begin{tabular}{c|c|c|c|c|c|c|c|c|} 
& & \multicolumn{3}{|c|}{ Idade } & \multicolumn{3}{c|}{ Sexo } \\
\cline { 2 - 9 } & $\mathbf{n}$ & $\mathbf{( \% )}$ & & $\mathbf{n}$ & $\mathbf{( \% )}$ & & $\mathbf{n}$ & $\%$ \\
\cline { 2 - 9 } $\begin{array}{c}\text { Estudantes } \\
\text { do } \\
\text { primeiro } \\
\text { ano }\end{array}$ & 76 & 100 & $17-21$ & 69 & 91 & Masculino & 16 & 21 \\
\cline { 4 - 9 } & & & $22-25$ & 7 & 9 & Feminino & 60 & 79 \\
\hline
\end{tabular}

A Tabela 2 mostra a experiência e o conhecimento dos alunos sobre traumatismo dentário. Dentre os estudantes do primeiro ano, 16 (21\%) disseram que tiveram informação sobre traumatismo dentário em aulas do curso de odontologia e apenas 7 (9\%) dos acadêmicos receberam informações sobre avulsão dentária. Perguntados sobre o que eles achavam ser a avulsão dentária, 46 (61\%) dos alunos responderam ser o deslocamento total para fora do alvéolo.

Tabela 2 - Experiências e conhecimento dos alunos sobre traumatismo dentário.

\begin{tabular}{|c|c|c|c|}
\hline \multirow{2}{*}{ Questões } & \multirow{2}{*}{ Respostas } & \multicolumn{2}{|c|}{ Alunos } \\
\hline & & $\mathbf{n}$ & $\%$ \\
\hline \multirow{7}{*}{$\begin{array}{l}\text { 3. Já ouviu falar sobre } \\
\text { traumatismo dentários } \\
\text { antes dessa } \\
\text { abordagem? }\end{array}$} & Sim, no dentista & 19 & 25 \\
\hline & Sim, na internet & 14 & 18 \\
\hline & Sim, na família & 8 & 10 \\
\hline & Sim, em cursos, aulas, leituras & 16 & 21 \\
\hline & Sim, na clínica odontológica & 4 & 5 \\
\hline & Sim, em algum caso conhecido & 4 & 5 \\
\hline & Não & 29 & 38 \\
\hline \multirow{2}{*}{$\begin{array}{l}\text { 4. Já ouviu falar sobre } \\
\text { avulsão dentária antes } \\
\text { dessa abordagem? }\end{array}$} & Sim, no dentista & 7 & 9 \\
\hline & Não & 69 & 91 \\
\hline \multirow{4}{*}{$\begin{array}{l}\text { 5. O que você acha que } \\
\text { é uma avulsão } \\
\text { dentária? }\end{array}$} & $\begin{array}{l}\text { Deslocamento do dente para } \\
\text { dentro do seu alvéolo }\end{array}$ & 7 & 9 \\
\hline & $\begin{array}{l}\text { Deslocamento do dente para um } \\
\text { dos lados do alvéolo }\end{array}$ & 5 & 7 \\
\hline & $\begin{array}{l}\text { Deslocamento parcial para fora } \\
\text { do alvéolo }\end{array}$ & 18 & 24 \\
\hline & $\begin{array}{l}\text { Deslocamento total para fora do } \\
\text { alvéolo }\end{array}$ & 46 & 61 \\
\hline \multirow{3}{*}{$\begin{array}{l}\text { 6. Você acha que a } \\
\text { avulsão dentária se } \\
\text { classifica em qual grau } \\
\text { de complexidade? }\end{array}$} & Baixa complexidade & 1 & 1 \\
\hline & Média complexidade & 25 & 33 \\
\hline & Alta complexidade & 50 & 66 \\
\hline \multirow{2}{*}{$\begin{array}{l}\text { 7. Você acredita que a } \\
\text { avulsão dentária possa } \\
\text { causar alguma } \\
\text { sequela? }\end{array}$} & Sim & 69 & 91 \\
\hline & Nao & 7 & 9 \\
\hline \multirow{2}{*}{$\begin{array}{l}\text { 8. Teve alguma } \\
\text { informação sobre } \\
\text { primeiros socorros de } \\
\text { dentes avulsionados? }\end{array}$} & Sim & 1 & 1 \\
\hline & Não & 75 & 99 \\
\hline
\end{tabular}

Considerando a classificação do grau de complexidade da avulsão dentária, a maioria dos graduandos (66\%) afirmou ser de alta complexidade; $25(33 \%)$ de média complexidade e 1 (um \%) optou pela opção de baixa complexidade. Perguntados se acreditavam que a avulsão poderia causar alguma sequela, a maioria $69(91 \%)$ responderam que sim. Apenas $1(1 \%)$ estudante teve informações sobre 
primeiros socorros de dentes avulsionados.

As Tabelas 3 e 4 mostram o conhecimento dos alunos sobre ações que devem ser tomadas em caso de avulsão dentária. Nenhum dos alunos do primeiro ano relatou que eles reimplantaria o dente imediatamente. A maioria deles $(27 \%)$ escolheram a opção de que não reposicionaria o dente no alvéolo, mas guardaria enrolado em um papel/gaze umedecido para depois levar ao dentista. Para 54\% dos alunos, um dente avulsionado deve ser colocado em soro fisiológico e para $33 \%$ armazenado em água filtrada ou destilada. Nenhum estudante escolheu a opção leite e apenas $5 \%$ marcou a opção saliva.

Questionados sobre o que fariam caso resolvessem reposicionar o dente de volta ao seu local, $34 \%$ dos alunos optaram por lavar o dente com soro fisiológico. Outros $28 \%$ escolheram que escovaria o dente suavemente com uma escova de dente e água/água filtrada/soro fisiológico. Sobre qual seria a melhor conduta quanto ao tempo para a realização reimplante, $53 \%$ dos graduandos optaram por realizar o reimplante imediato, $27 \%$ realizar o reimplante em até 60 minutos e $13 \%$ esperar 1 dia para realizar o reimplante. Perguntados se seriam capazes de realizar o reposicionamento do dente, $88 \%$ responderam que não. E por onde manipularia o dente avulsionado, $91 \%$ respondeu pela coroa.

Tabela 3 - Conhecimento dos alunos sobre manejo de avulsão dental.

\begin{tabular}{|c|c|c|c|}
\hline \multirow{2}{*}{ Questões } & \multirow{2}{*}{ Respostas } & \multicolumn{2}{|c|}{ Alunos } \\
\hline & & $\mathbf{n}$ & $\%$ \\
\hline \multirow{10}{*}{$\begin{array}{l}\text { 9. O que faria se } \\
\text { presenciasse um caso } \\
\text { em que o dente saiu } \\
\text { por completo da boca, } \\
\text { após um traumatismo? }\end{array}$} & Nada, jogaria o dente fora & o & o \\
\hline & $\begin{array}{l}\text { Guardaria o dente, mas não } \\
\text { levaria ao dentista }\end{array}$ & o & $\mathrm{o}$ \\
\hline & $\begin{array}{l}\text { Não reposicionaria o dente no } \\
\text { alvéolo, mas levaria o dente na } \\
\text { mão até o dentista }\end{array}$ & o & $\mathrm{o}$ \\
\hline & $\begin{array}{l}\text { Não reposicionaria o dente no } \\
\text { alvéolo, mas guardaria enrolado } \\
\text { em um papel / pano / gaze seco } \\
\text { para depois levar ao dentista }\end{array}$ & 18 & 24 \\
\hline & $\begin{array}{l}\text { Não reposicionaria o dente no } \\
\text { alvéolo, mas guardaria enrolado } \\
\text { em um papel / pano / gaze } \\
\text { umedecido para depois levar ao } \\
\text { dentista }\end{array}$ & 20 & 27 \\
\hline & $\begin{array}{l}\text { Não reposicionaria o dente no } \\
\text { alvéolo, mas guardaria o dente } \\
\text { em um recipiente a seco para } \\
\text { depois levar ao dentista }\end{array}$ & 16 & 21 \\
\hline & $\begin{array}{l}\text { Não reposicionaria o dente no } \\
\text { alvéolo, mas guardaria o dente } \\
\text { em um recipiente líquido para } \\
\text { depois levar ao dentista }\end{array}$ & 14 & 16 \\
\hline & $\begin{array}{l}\text { Não reposicionaria o dente no } \\
\text { alvéolo, mas guardaria o dente } \\
\text { em um recipiente envolto em gelo } \\
\text { para depois levar ao dentista }\end{array}$ & 6 & 8 \\
\hline & $\begin{array}{l}\text { Não reposicionaria o dente no } \\
\text { alvéolo, mas guardaria o dente na } \\
\text { boca da vítima até ir ao dentista }\end{array}$ & 2 & 3 \\
\hline & $\begin{array}{l}\begin{array}{l}\text { Reposicionaria } \\
\text { mesmo lugar }\end{array} \\
\end{array}$ & o & $\mathrm{o}$ \\
\hline \multirow{11}{*}{$\begin{array}{l}\text { 10. Caso colocasse em } \\
\text { um meio líquido, qual } \\
\text { seria? }\end{array}$} & Água de torneira & 2 & 3 \\
\hline & Água filtrada ou destilada & 25 & 33 \\
\hline & Soro fisiológico & 41 & 54 \\
\hline & Leite & o & o \\
\hline & Água sanitária & 1 & 1 \\
\hline & Detergente & o & $\mathrm{o}$ \\
\hline & Álcool & 2 & 3 \\
\hline & Água de coco & 0 & $\mathrm{o}$ \\
\hline & Saliva & 4 & 5 \\
\hline & Água Oxigenada & o & $\mathrm{o}$ \\
\hline & Não responderam & 1 & 1 \\
\hline
\end{tabular}

Tabela 4 - Conhecimento dos alunos sobre manejo de avulsão dental.

\begin{tabular}{|c|c|c|c|}
\hline \multirow{2}{*}{ Questões } & \multirow{2}{*}{ Respostas } & \multicolumn{2}{|c|}{ Alunos } \\
\hline & & $\mathbf{n}$ & $\%$ \\
\hline \multirow{12}{*}{$\begin{array}{l}\text { 11. Se você resolvesse } \\
\text { reposicionar o dente } \\
\text { de volta no seu local }\end{array}$} & $\begin{array}{l}\text { Enxaguaria o dente em água de } \\
\text { torneira }\end{array}$ & 2 & 3 \\
\hline & $\begin{array}{l}\text { Lavaria o dente em água corrente } \\
\text { filtrada }\end{array}$ & 11 & 14 \\
\hline & $\begin{array}{l}\text { Lavaria o dente com } \\
\text { fisiológico }\end{array}$ & 26 & 34 \\
\hline & $\begin{array}{l}\text { Lavaria o dente com pasta de } \\
\text { dente, sabão ou detergente }\end{array}$ & o & o \\
\hline & $\begin{array}{l}\text { Lavaria o dente com pasta de } \\
\text { dente, sabão ou detergente e água }\end{array}$ & 1 & 1 \\
\hline & $\begin{array}{l}\text { Lavaria o dente com pasta de } \\
\text { dente, sabão ou detergente e água } \\
\text { filtrada }\end{array}$ & 2 & 3 \\
\hline & $\begin{array}{l}\text { Lavaria o dente com pasta de } \\
\text { dente, sabão ou detergente e soro } \\
\text { fisiológico }\end{array}$ & 2 & 3 \\
\hline & $\begin{array}{l}\text { Escovaria o dente suavemente } \\
\text { com uma escova de dente }\end{array}$ & 3 & 4 \\
\hline & $\begin{array}{l}\text { Escovaria o dente suavemente } \\
\text { com uma escova de dente e água } \\
\text { / água filtrada / soro fisiológico }\end{array}$ & 21 & 28 \\
\hline & $\begin{array}{l}\text { Escovaria o dente suavemente } \\
\text { com uma escova de dente e água } \\
\text { / água filtrada / soro fisiológico e } \\
\text { pasta de dente / sabão ou } \\
\text { detergente }\end{array}$ & 3 & 4 \\
\hline & $\begin{array}{l}\text { Reposicionaria o dente no alvéolo } \\
\text { sem fazer nada }\end{array}$ & 4 & 5 \\
\hline & Não responderam & 1 & 1 \\
\hline \multirow{5}{*}{$\begin{array}{l}\text { 12. Qual a melhor } \\
\text { conduta em relação ao } \\
\text { tempo para realização } \\
\text { do reimplante? }\end{array}$} & Realizar o implante imediato & 40 & 53 \\
\hline & $\begin{array}{l}\text { Realizar o reimplante em até } 60 \\
\text { minutos }\end{array}$ & 21 & 27 \\
\hline & $\begin{array}{l}\text { Esperar 6o minutos para } \\
\text { reimplantar o dente }\end{array}$ & 2 & 3 \\
\hline & $\begin{array}{l}\text { Esperar } 1 \text { dia para realizar o } \\
\text { implante }\end{array}$ & 10 & 13 \\
\hline & Não responderam & 3 & 4 \\
\hline \multirow{3}{*}{$\begin{array}{l}\text { 13. Você se acha capaz } \\
\text { de realizar o } \\
\text { reposicionamento do } \\
\text { dente? }\end{array}$} & Sim & 8 & 11 \\
\hline & Nao & 67 & 88 \\
\hline & Não responderam & 1 & 1 \\
\hline \multirow{4}{*}{$\begin{array}{l}\text { 14. Por onde você } \\
\text { manipularia o dente } \\
\text { que saiu da boca? }\end{array}$} & Coroa & 69 & 91 \\
\hline & Raiz & 3 & 4 \\
\hline & Coroa e raiz & o & o \\
\hline & Não responderam & 4 & 5 \\
\hline
\end{tabular}

\section{DISCUSSÃO}

As condutas frente a um caso de avulsão dentária são necessárias para ajudar os dentistas, bem como outros profissionais da saúde bucal, a oferecer o melhor atendimento possível e de maneira mais eficiente $^{8}$. Dessa forma, é importante promover conscientização e informações atualizadas aos profissionais, em relação às modalidades de tratamento de emergência. A capacidade em aplicar as técnicas corretas imediatamente após a lesão traumática deve melhorar o prognóstico do caso.

Neste estudo, os resultados revelaram um padrão desigual de conhecimento dos alunos do primeiro ano sobre a avulsão dentária. A pesquisa mostrou que a maioria dos alunos $91 \%$ e $99 \%$ não tinham ouvido falar sobre avulsão dentária antes desta abordagem e nem recebido informações sobre primeiros socorros em dentes avulsionados, respectivamente. Questionados sobre o que seriam a avulsão dentária, apenas $61 \%$ marcou a alternativa correta indicando ser o deslocamento total do dente para fora do seu alvéolo.

Avulsão é um deslocamento completo de um dente de sua cavidade alveolar como resultado de trauma e normalmente, o dente avulsionado também 
é deslocado completamente para fora da boca. Protocolos de manejo devem incluir o manuseio das células da polpa e do ligamento periodontal, sendo este último muito mais importante, pois essas células são essenciais para a cicatrização dos dentes avulsionados reimplantados, melhorando a sobrevida em longo prazo e o prognóstico dos dentes avulsionados ${ }^{9}$.

Questionados sobre o que fariam quando presenciasse um caso de avulsão após um traumatismo, nenhum dos alunos relatou que eles reimplantariam o dente imediatamente. E a maioria (27\%) não reposicionaria o dente no alvéolo, mas guardaria enrolado em um papel/gaze umedecido para depois levar ao dentista. De acordo com a literatura, o reimplante de um dente dentro de 5 minutos normalmente assegura o retorno imediato das células do ligamento periodontal à função normal ${ }^{8}$. Entretanto, após mais de 15 minutos de armazenamento a seco, o precursor, progenitor ou células-tronco não são mais capazes de se diferenciar em fibroblastos ${ }^{10,11}$. E após 30 minutos de armazenamento a seco, virtualmente todas as células do ligamento periodontal provavelmente se tornam necróticas ${ }^{12,13}$.

A duração do armazenamento extra-oral de um dente avulsionado é identificada como crítica para a cicatrização dos tecidos ${ }^{3,14,15}$. Sendo que o reimplante imediato destes dentes impacta positivamente na viabilidade das células do ligamento periodontal e resulta em cicatrização das mesmas em até $85 \%$ dos dentes permanentes ${ }^{3}$.

Entretanto, quando o reimplante imediato não é possível, o meio de armazenamento do dente avulsionado pode influenciar diretamente no resultado do reimplante. Para 54\% dos alunos, um dente avulsionado deve ser colocado em soro fisiológico e para 33\% armazenado em água filtrada ou destilada. Nenhum estudante escolheu a opção leite e apenas $5 \%$ marcou a opção saliva.

As condições extra-alveolares dos dentes avulsionados podem ser modificadas armazenando o dente em um meio considerado fisiológico ${ }^{16}$. Vários meios de armazenamento foram propostos para o transporte de dentes após a avulsão. O meio de armazenamento ideal deve preservar a vitalidade celular, aderência e capacidade clonogênica e deve estar prontamente disponível ou facilmente acessível no local de um acidente ${ }^{17}$.

$\mathrm{O}$ leite, não assinalado por nenhum estudante, como meio de armazenamento é o meio de transporte mais prático para o armazenamento a curto prazo de dentes avulsionados, devido à sua disponibilidade imediata em quase todas as situações $^{18}$. O leite possui uma combinação única de nutrientes, capaz de manter a viabilidade das células periodontais, e com seu $\mathrm{pH}$ fisiológico de 6,5 a 7,2, pode ser considerado como o melhor meio de armazenamento na maioria das situações ${ }^{19}$. O leite pode potencialmente manter a viabilidade das células periodontais por até 2 horas $^{20}$, e se resfriado esse tempo pode aumentar em até 45 minutos ${ }^{11,21}$.

A solução balanceada de Hank's (HBSS) é uma solução salina com $\mathrm{pH}$ equilibrado, contendo todos os metabólitos essenciais e glicose necessários para a manutenção das células. A vitalidade, capacidade clonogênica e mitogênica das células periodontais utilizando este meio são excelentes. O HBSS não precisa ser refrigerado e pode preservar um dente avulsionado por pelo menos 24 horas $^{22,23}$. No entanto, o acesso a esta solução para propósitos de primeiros socorros é uma grande desvantagem ${ }^{24}$, isso porque o HBSS é usado em laboratórios de pesquisa e não está prontamente disponível para o público em geral, embora haja um kit especial disponível em alguns países, que foi projetado para emergências de dentes avulsionados ${ }^{25}$.

Dois estudantes assinalaram a água de torneira como meio de armazenamento do dente avulsionado, porém ela não é compatível com células periodontais e por ser hipotônica causa rápida lise celular $^{18,26}$. Apesar de alguns estudos sugerirem como meio de armazenamento por períodos muito breves, quando não há alternativas, ele ainda é o meio de armazenamento menos desejável disponível ${ }^{26,27}$.

O meio saliva foi assinalado por 4 estudantes, e ela pode ser utilizada como um meio imediato intermediário de armazenamento ${ }^{11}$. Embora ela esteja prontamente disponível, os dentes avulsionados não devem ser armazenados por mais de 30 minutos na saliva, pois ela contém substâncias potencialmente nocivas, como enzimas, bactérias e seus subprodutos $^{22}$.

O soro fisiológico foi o meio mais escolhido pelos estudantes (54\%). Possui uma osmolaridade compatível com as células do ligamento periodontal, no entanto, ao contrário do HBSS e leite, ele não contém nutrientes $^{25}$. O soro parece ser adequado para o armazenamento de dentes avulsionados em curto prazo, pois manterá a vitalidade das células por cerca de 2 horas, mas é potencialmente prejudicial se as células forem armazenadas por mais tempo do que isso $^{22}$.

A água de coco, não foi assinalada por nenhum estudante, ela é biologicamente pura, estéril e rica em aminoácidos, proteínas, vitaminas e minerais. Como resultado de sua alta osmolaridade, composição e pronta aceitação pelo corpo humano, a água de coco tem sido estudada como um meio de armazenamento provisório potencial para dentes avulsionados, mas o $\mathrm{pH}$ de 4,1 é prejudicial ao metabolismo celular ${ }^{25}$. Os estudos têm demonstrado resultados contraditórios sobre o seu uso ${ }^{28-33}$. Dessa forma, é difícil considerar a água de coco como um meio de armazenamento adequado para dentes avulsionados. 
Questionados o que fariam antes de posicionar o dente de volta ao seu local, a maioria (34\%) assinalou que lavaria o dente com soro fisiológico. Sobre qual seria a melhor conduta quanto ao tempo para a realização do reimplante, 53\% marcaram o reimplante imediato. E sobre por onde manipularia o dente avulsionado, 91\% escolheu a opção pela coroa.

De acordo com a Associação Internacional de Traumatologia Dentária (International Association of Dental Traumatology - IADT), após a avulsão dentária o dente deve ser segurado pela coroa evitando tocar na parte radicular. Para um reimplante imediato, se o dente estiver sujo, deve-se lavar rapidamente por, no máximo, 10 segundos, em água corrente fria antes de reposicionar. Entretanto, se o dente foi mantido em um meio de armazenamento fisiológico e/ou foi mantido em local seco, com tempo extra-alveolar inferior a 60 minutos, deve-se limpar a superfície da raiz e o forame apical com solução salina e mergulhar o dente em soro fisiológico, removendo a contaminação e as células mortas da superfície radicular ${ }^{8}$.

Se o tempo extra-alveolar for maior que 60 minutos, o reimplante tardio tem um prognóstico desfavorável em longo prazo. O objetivo de realizar o reimplante é além de reabilitar o dente por razões estéticas, funcionais e psicológicas, a manutenção do contorno do osso alveolar. No entanto, o prognóstico esperado é de anquilose e reabsorção radicular com eventual perda do elemento dentário ${ }^{8}$.

\section{CONCLUSÃO}

Os resultados sugerem que o conhecimento sobre o manejo de lesões dentárias é insuficiente entre os estudantes do primeiro ano de Odontologia. Dessa forma, a educação odontológica deve-se utilizar de orientações sobre primeiros socorros e ressaltar a necessidade de divulgação de programas de treinamento e educação não apenas para os estudantes de Odontologia, mas também para o público em geral.

\section{REFERÊNCIAS}

1. Andreasen JO, Andreasen FM. Texto e Atlas colorido de traumatismo dental. $3^{\text {a }}$ ed. Porto Alegre: Artes Médicas; 2001.

2. Gutmann JL, Gutmann M. Cause, incidence, and prevention of trauma to teeth. Dent Clin North Am. 1995;39:1-13.

3. Andreasen JO, Borum MK, Jacobsen HL, Andreasen FM. Replantation of 400 avulsed permanent incisors. Factors related to periodontal ligament healing. Endod Dent Traumatol. 1995;11:76-89.

4. Chan AWK, Wong TKS, Cheung GSP. Lay knowledge of physical education teachers about the emergency management of dental trauma in Hong Kong. Dent Traumatol 2001;17:77-85.

5. Pohl Y, Filippi A, Kirschner H. Results after replantation of avulsed permanent teeth. II. Periodontal healing and the role of physiologic storage and antiresorptive - regenerative therapy. Dent Traumatol. 2005;21:93-101.

6. Cohenca, N. Knowledge of oral health professionals of treatment of avulsed teeth. Dent Traumatol. 2006;296-30.

7. Malmgren B, Malmgren O. Rate of infraposition of reimplanted ankylosed incisors related to age and growth in children and adolescents. Dent Traumatol. 2002;18:28-36.

8. Flores MT, Andreasen JO, Bakland LK, Feiglin B, Gutmann JL, Oikarinen K et al. International Association of Dental Traumatology. Guidelines for the evaluation and management of traumatic dental injuries. Dent Traumatol. 2001;17:193-8.

9. Ingle JI, Bakland LK, Baumgartner JC. Ingle's endodontics. 6th ed. Hamilton, ON: B.C. Decker Inc; 2008.

10. Lekic P, Kenny D, Moe HK, Barretti E, McCulloch CA. Relationship of clonogenic capacity to plating efficiency and vital dye staining of human periodontal ligament cells: implications for tooth replantation. J Periodontal Res. 1996;31:294-300.

11. Lekic PC, Kenny DJ, Barrett EJ. The influence of storage conditions on the clonogenic capacity of periodontal ligament cells: implications for tooth replantation. Int Endod J. 1998;31:137-40.

12. Layug ML, Barrett EJ, Kenny DJ. Interim storage of avulsed permanent teeth. J Can Dent Assoc. 1998;64:357-63.

13. Lin DG, Kenny DJ, Barrett EJ, Lekic P, McCulloch CA. Storage conditions of avulsed teeth affect the phenotype of cultured human periodontal ligament cells. J Periodontal Res. 2000;35:42-50.

14. Andreasen JO, Andreasen FM, Andersson L. Textbook and colour atlas of traumatic injuries to the teeth, 4th edn. Oxford: Blackwell Munksgaard; 2007.

15. Andersson L, Bodin I. Avulsed human teeth replanted within 15 minutes - a long term clinical follow-up study. Endod Dent Traumatol. 1990;6:37-42.

16. Courts FJ, Mueller WA, Tabeling HJ. Milk as an interim storage medium for avulsed teeth. Pediatr Dent. 1983;5:183-6.

17. Ashkenazi M, Marouni M, Sarnat H. In vitro viability, mitogenicity and clonogenic capacity of periodontal ligament cells after storage in four media at room temperature. Endod Dent Traumatol. 2000;16:63-70. 
18. Hammarström L, Pierce A, Blomlöf L, Feiglin B, Lindskog S. Tooth avulsion and replantation - a review. Endod Dent Traumatol. 1986;2:1-8.

19. Hiltz J, Trope M. Vitality of human lip fibroblasts in milk, hanks balanced salt solution and viaspan storage media. Dent Traumatol. 1991;7:69-72.

20. Blomlöf L. Milk and saliva as possible storage media for traumatically exarticulated teeth prior to replantation. Swed Dent J Suppl. 1981;8:1-26.

21. Huang SC, Remeikis NA, Daniel JC. Effects of long-term exposure of human periodontal ligament cells to milk and other solutions. J Endod. 1996;22:30-3.

22. Khademi AA, Saei S, Mohajeri MR et al. A new storage medium for an avulsed tooth. J Contemp Dent Pract. 2008;9:25-32.

23. Krasner PR. Avulsed teeth: improving the diagnosis. Dent Prod Rep. 2007;2:52-64.

24. Fagade OO. Extra-alveolar storage media for tooth autotransplants and replants. Internet $\mathrm{J}$ Dent Sci. 2005;2:1-10.

25. Udoye CI, Jafarzadeh H, Abbott PV. Transport media for avulsed teeth: A review. Aust Endod J. 2012;38:129-136.

26. Blomlöf L, Andersson L, Lindskog S, Hedström KG, Hammarström L. Periodontal healing of replanted monkey teeth prevented from drying. Acta Odontol Scand. 1983;41:117-23.

27. Bibby KJ, McCulloch CA. Regulation of cell volume and $[\mathrm{Ca} 2+]$ in attached human fibroblasts responding to anisosmotic buffers. Am J Physiol. 1994;266:39-49

28. Gopikrishna V, Baweja PS, Venkateshbabu N, Thomas T, Kandaswamy D. Comparison of coconut water, propolis, HBSS, and milk on PDL cell survival. J Endod. 2008;34:587-589.

29. Gopikrishna V, Thomas T, Kandaswamy D. A quantitative analysis of coconut water: a new storage media for avulsed teeth. Oral Surg Oral Med Oral Pathol Oral Radiol Endod. 2008;105:61-65.

30. Moreira-Neto JJS, Gondim JO, Raddi MSG, Pansani CA. Viability of human fibroblasts in coconut water as storage medium. Intern Endod J. 2009;42:827-830.

31. Thomas T, Gopikrishna V, Kandaswamy D. Comparative evaluation of maintenance of cell viability of an experimental transport media "coconut water" with Hank's balanced salt solution and milk, for transportation of an avulsed tooth: an in vitro cell culture study. J Conserv Dent. 2008;11:22-29.

32. Souza BDM, Luckemeyer DD, Reyes-Carmona JF, Felippe WT, Simões CMO, Felippe MCS. Viability of human periodontal ligament fibroblasts in milk, Hank's balanced salt solution and coconut water as storage media. Int Endod $\mathrm{J}$. 2011; 44:111-115.

33. Pearson RM, Liewehr FR, West LA, Patton WR, McPherson JC, Runner RR. Human periodontal ligament cell viability in milk and milk substitutes. J Endod. 2003; 29:184-186.

\section{CONFLITO DE INTERESSES}

Os autores declaram não haver conflitos de interesse.

\section{AUTOR PARA CORRESPONDÊNCIA}

\section{Maria Luisa Gomes Ferreira}

Universidade Estadual de Maringá, UEM, Departamento de Odontologia,

87083-170 Maringá - PR, Brasil

E-mail: malu.odt@gmail.com
Submetido em 09/08/2019

Aceito em 20/04/2020 